\title{
Zoon's Balanitis Treated With Erbium:YAG Laser Ablation
}

\author{
John G. Albertini, MD, MC, USAF, ${ }^{1 *}$ David E.E. Holck, MD, MC, USAF, ${ }^{2}$ and Mary F. Farley, MD, MC, USA ${ }^{1}$ \\ ${ }^{1}$ Department of Dermatology, Brooke Army Medical Center, Fort Sam Houston, Texas 78234 \\ ${ }^{2}$ Department of Ophthalmology, Wilford Hall USAF Medical Center, Lackland AFB, Texas 78236
}

Background and Objective: Zoon's balanitis (ZB) is an uncommon, benign, idiopathic inflammatory condition affecting uncircumcised males. Definitive treatments include circumcision and carbon dioxide $\left(\mathrm{CO}_{2}\right)$ laser ablation. We describe an alternative laser modality showing efficacy in the treatment of ZB.

Study Design/Materials and Methods: We report the first case of $\mathrm{ZB}$ effectively treated with Erbium:YAG (Er:YAG) laser ablation. We review the pathogenesis and medical, surgical, and laser management of ZB.

Results: Our patient demonstrated a long-term clinical and histologic cure after Er:YAG laser ablation of ZB.

Conclusions: As an alternative to circumcision or continuous wave $\mathrm{CO}_{2}$ laser, we propose a trial of Er:YAG laser ablation as a low risk, first line treatment of ZB. Lasers Surg. Med. 30:123-126, 2002.

(C) 2002 Wiley-Liss, Inc.

Key words: carbon dioxide laser; plasma cell balanitis; Erbium:YAG laser

\section{INTRODUCTION}

Zoon's balanitis (ZB), also known as plasma cell balanitis, is a relatively uncommon, idiopathic inflammatory condition. ZB primarily affects the glans penis in uncircumcised males, who present with red-orange, smooth or eroded plaques [1-10]. ZB occasionally causes pruritis or discomfort. $\mathrm{CO}_{2}$ laser ablation of $\mathrm{ZB}$ is an effective treatment [11] and may be preferable to circumcision $[10,12,13]$ in the management of this disease. We present a case illustrating that superficial laser ablation with a newer generation of resurfacing lasers may be as effective as traditional continuous-wave $\mathrm{CO}_{2}$ ablation, with less morbidity, thermal damage, and risk of scarring.

\section{CASE REPORT}

The Urology department referred a 67-year-old Caucasian male for treatment of squamous cell carcinoma in-situ or erythroplasia of Queyrat (EQ) of the glans penis. He was clinically diagnosed with EQ in 1988 and treated with 5fluorouracil cream (5-FU). Local recurrence in 1991 was biopsied and showed EQ. $\mathrm{CO}_{2}$ laser ablation was performed, and repeated in 1993 for another local recurrence. Following these procedures, he was treated twice more with 5-FU topically and appeared to clear completely. His presenting eruption evolved for several months prior to his Urology evaluation. Examination revealed a $23 \times 17 \mathrm{~mm}$ smooth, brick-red, perimeatal plaque (Fig. 1). His medical history and cutaneous examination were otherwise unremarkable.

The clinical differential diagnosis included plasma cell balanitis/Zoon's balanitis (ZB), psoriasis, and candidiasis, in addition to EQ. Shave biopsy was consistent with ZB, showing characteristic histologic features of a thinned, effaced epithelium overlying a dense, lichenoid plasma cell infiltrate, telangectasias and hemosiderin deposition. The patient failed 5 months of topical treatment with potent corticosteroids and mupirocin ointment. After the patient requested alternatives to circumcision, we treated the balanitis with Er:YAG laser ablation (Derma-K, ESC Sharplan, $2940 \mathrm{~nm}, 350 \mathrm{~ms}$ ).

After EMLA application and local infiltration of $1 \%$ plain lidocaine, we treated the balanitis with 3-6 overlapping passes using the lowest power settings $\left(0.5 \mathrm{~J} / \mathrm{cm}^{2} ; 3 \mathrm{~mm}\right.$ spot size; $5 \mathrm{~Hz}$ ) (Figs. 2 and 3). He healed well and completely reepithelialized within one week. A confirmatory shave biopsy after 2-months showed no residual balanitis. At 4-months, his exam revealed a perimeatal erythematous smooth plaque, which was retreated with two more passes of ablation (same settings). The plaque resolved and 1 month later a biopsy of the residual perimeatal erythema showed no evidence of ZB (Fig. 4). He remains disease free after more than 2 years follow-up.

\section{DISCUSSION}

The exact etiology of $\mathrm{ZB}$ is unknown, but heat, friction, and poor hygiene are considered pathogenic factors [6,7]. Irritation by smegma, urine or external contacts and normal colonizing organisms that become pathogenic under favorable host conditions may also play a contributory role $[14,15]$. The proclivity of $\mathrm{ZB}$ for the uncircumcised and the consistent response to circumcision lend support to this theory $[6-8,12]$. In one case, incomplete circumcision cleared the majority of $\mathrm{ZB}$, but resulted in persistent disease in the area of glans and prepuce still covered by foreskin [12]. Chronic infection with mycobacterium smegmatis has been postulated as the cause of ZB [15]. Recent

*Correspondence to: Maj. John G. Albertini, MD, MC, USAF, Department of Dermatology, Brooke Army Medical Center, Fort Sam Houston, TX 78234.

E-mail: John.Albertini@cen.amedd.army.mil

Accepted 6 December 2001

This article is a US Government work and, as such, is in the public domain in the United States of America. 


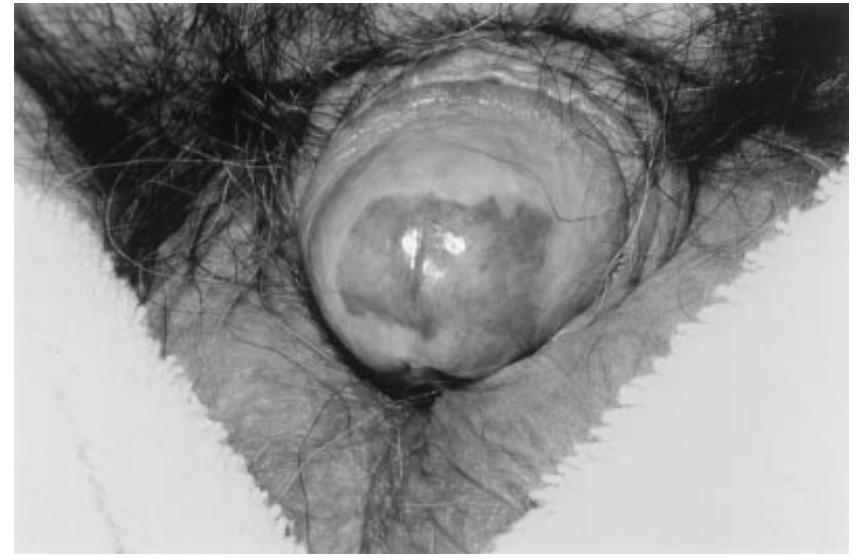

Fig. 1. Solitary, smooth, red-orange plaque on perimeatal glans penis consistent with Zoonís balanitis.

attempts to isolate $m$. smegmatis have been unsuccessful [8]. Yoganathan et al. conclude that trauma is most significant in the pathogenesis of plasma cell balanitis and vulvitis [8]. They noted a concentration of disease on the dorsal glans penis, where foreskin friction is greatest. One of their female patients developed plasma cell vulvitis circumferentially around her vulva immediately after a traumatic vaginal delivery.

The unclear etiology of ZB and the multiple contributory factors make it difficult to find specific therapeutic targets. Promotion of good hygiene is an easy and potentially beneficial measure. Patients should be instructed to retract the foreskin regularly and perform gentle cleansing of the entire glans, preputial sac, and foreskin. Many local, topical therapies have been reported, but rarely provide more than temporary control. Mid-potency and high-potency topical corticosteroids have been used for many years as a first line measure, producing variable clinical improvement but rarely long-term cures [8]. Topical antimicrobial preparations including antibacterial and antifungal creams have largely proven ineffective.

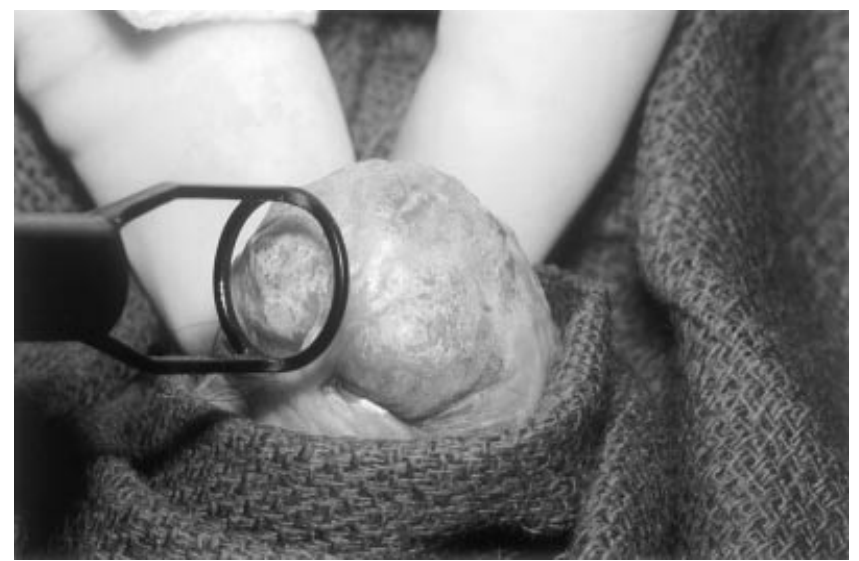

Fig. 2. Laser ablation of Zoonís balanitis with Erbium:YAG laser.

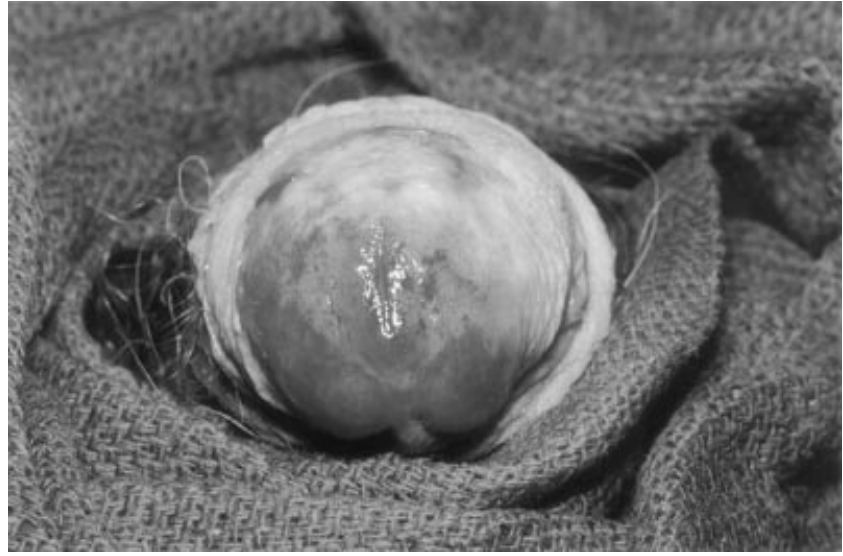

Fig. 3. Superficial, pure ablation with minimal post-operative bleeding.

Fusidic acid is a combination anti-inflammatory and antibiotic agent sharing a similar molecular structure with corticosteroids. Fusidic acid $2 \%$ cream has induced both suppression and 6 months cures in 5 of 8 patients, despite an unclear mechanism of action [16]. Radiotherapy and local destructive modalities, such as electrosurgery, have rarely proven effective.

Circumcision has proven the most consistently effective, long-term cure for ZB [7,10,12,13]. In 1984, Ferrandiz and Ribera reported cures in seven consecutive patients undergoing circumcision for $\mathrm{ZB}$, with an average follow-up of 12 months [12]. Murray et al. cured five consecutive patients with circumcision, two of whom had previously failed a dorsal slit procedure [7]. Urologists may regard circumcision as the treatment of choice [17].

In $1989, \mathrm{CO}_{2}$ laser ablation was reported as an effective alternative to circumcision [11]. They used the defocused mode of the continuous wave $\mathrm{CO}_{2}$ laser at an irradiance of $200 \mathrm{~W} / \mathrm{cm}^{2}$ to produce "highly precise vaporization" and "selective damage of the target area" [ZB] [11]. The continuous wave $\mathrm{CO}_{2}$ laser, however, carries a significant

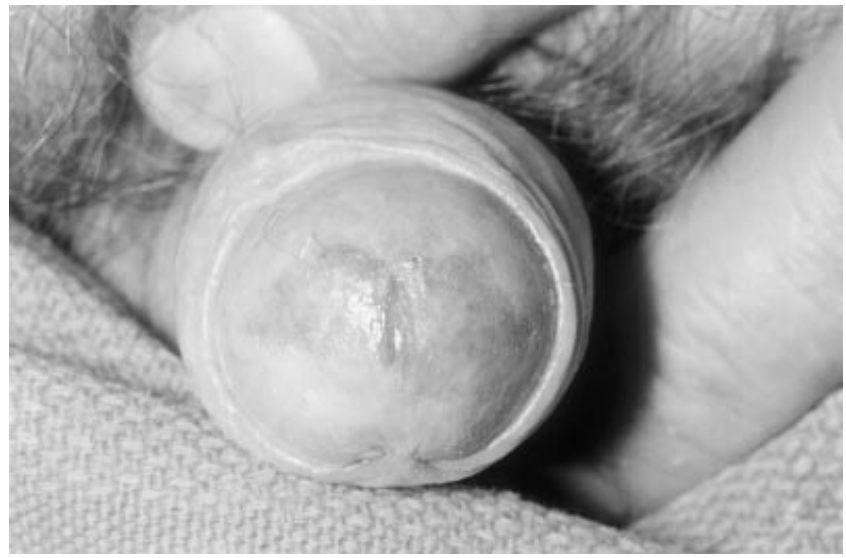

Fig. 4. Short term, post-operative erythema without clinical or histologic evidence of residual Zoonís balanitis. 
risk of scarring because its prolonged tissue dwell-time causes collateral thermal damage $(200-300 \mathrm{~mm})[18,19]$. Irradiation of the skin surface by the Er:YAG laser produces relatively pure ablation with minimal thermal damage [19-24]. Because ablation is directly proportional to fluence, the Er:YAG laser can be finely adapted to the clinical scenario. Several studies demonstrate that superficial cutaneous wounds produced by the Er:YAG laser or cold steel surgery reepithelialize at equivalent rates and without scarring [25-27].

Ablation depth varies with laser and tissue properties, but with the short-pulsed ( $\sim 100-300$ milliseconds) Er:YAG laser above the ablative threshold $\left(\sim 1.5 \mathrm{~J} / \mathrm{cm}^{2}\right)$, single impacts generally ablate $5-50 \mathrm{~mm}$ with residual thermal damage measuring 5-40 $\mathrm{mm}$ [19-25,28-35]. These ablation and coagulation depths apply for typical dermatologic settings $\left(1-10 \mathrm{~J} / \mathrm{cm}^{2}\right)$. While the fluence $\left(0.5 \mathrm{~J} / \mathrm{cm}^{2}\right)$ used in our patient is below the standard ablation threshold for keratinizing human skin, it approaches the range for guinea pig skin $\left(0.6-1.5 \mathrm{~J} / \mathrm{cm}^{2}\right)[20]$. This fluence and the highly overlapping pattern appeared sufficient to superficially ablate mucosal epithelium, which lacks a hydrophobic orthokeratotic stratum corneum, which may have a slightly higher water content due to increased intracellular glycogen, and which may possess slightly weaker structural integrity than typical epidermis. Our mechanical wiping may also have contributed to the removal of some thermally denatured, non-vaporized, epithelium. While our clinical and pathological results confirm the efficacy of our parameters and technique, using a definitively ablative fluence may prove more efficient for treating this process.

The Er:YAG laser emits energy in the mid-infrared invisible light spectrum with a wavelength of $2,940 \mathrm{~nm}$, which corresponds closely with an absorption peak for water [36]. The peak water absorption coefficient is 13 times greater for the Er:YAG than for the $\mathrm{CO}_{2}$ laser $[20,37]$. Epidermis is composed of $\sim 70 \%$ water by volume, making it highly susceptible to ablation with the Er:YAG laser [21]. Because epidermal ablation is so efficient, peripheral thermal damage is limited to a very narrow zone. Recent work has shown that repetitive Er:YAG laser irradiation with pulse-stacking of low fluences can cause deep coagulation of dermal collagen [38]. When treating $\mathrm{ZB}$, proper technique should prevent this effect and scarring is unlikely, because bleeding serves as a safeguard against deep ablation. Despite the highly vascular penile tissue, our negligible intra-operative bleeding demonstrates the precise and superficial ablation possible with the Er:YAG laser. ZB represents an epithelial process and the glans penis lacks adnexal structures that might harbor residual disease and that contribute to reepithelialization. Deep ablation is neither necessary nor desirable. The focal perimeatal recurrence likely resulted from mild urethral extension and it was easily retreated. Finally, smoke evacuation and properly fitted, and filtered masks are critical in this setting because of the significant plume produced and the risk of subclinical pathogenic microorganisms on genital skin.

\section{CONCLUSIONS}

As an alternative to definitive circumcision, we propose a trial of Er:YAG laser ablation as a low risk, first line treatment of $\mathrm{ZB}$, replacing the far more thermally destructive $\mathrm{CO}_{2}$ laser. The Er:YAG laser is ideally suited to selectively remove the diseased epithelium of the glans penis without risk of scarring. We also emphasize the need for histologic confirmation of clinical diagnoses, as this patient was referred for Mohs micrographic surgery of EQ that was subsequently diagnosed as ZB pathologically.

\section{REFERENCES}

1. Zoon JJ. Balanaposthite chronique circonscrite benigne a plasmocytes (contra erythroplasie de Queyrat). Dermatologica 1952;105:1-7.

2. Garnier G. Benign plasma-cell erythroplasia. Br J Dermatol 1957;69:77-80.

3. Stern JK, Rosen T. Balanitis plasmacellularis circumscripta (Zoon's balanitis plasmacellularis). Cutis 1980;25:57-60.

4. Brodin MB. Balanitis circumscripta plasmacellularis. J Am Acad Dermatol 1980;2:33-35.

5. Souteyrand P, Wong E, MacDonald DM. Zoon's balanitis (balanitis circumscripta plasmacellularis). Br J Dermatol 1981;105:195-199.

6. Jolly BB, Krishnamurty S, Vaidyanathan S, Zoon's balanitis Urol Int 1993;50:182-184.

7. Murray JG, Fletcher MS, Yates-Bell AJ, Pryor JP, Darby AJ, Packham DA. Br J Urol 1986;58:689-691.

8. Yoganathan S, Bohl TG, Mason G. Plasma cell balanitis and vulvitis (of Zoon). A study of 10 cases. J Reprod Med 1994; 39:939-944.

9. Horan DB, Redman JF, Jansen GT. Papulosquamous lesions of glans penis. Urology 1984;23:1-4.

10. Kumar B, Sharma R, Rajagopalan M, Radotra BD. Plasma cell balanitis: Clinical and histopahtological featuresóresponse to circumcision. Genitourin Med 1995;71:32-34.

11. Baldwin HE, Geronemus RG. The treatment of Zoon's balanitis with the carbon dioxide laser. J Dermatol Surg Oncol 1989;15:491-494.

12. Ferrandiz C, Ribera M. Zoon's balanitis treated by circumcision. J Dermatol Surg Oncol 1984;10:622-625.

13. Sonnex TS, Dawber RP, Ryan TJ, Ralfs IG. Zoon's (plasmacell) balanitis: Treatment by circumcision. British Journal of Dermatology 1982;106:585-588.

14. Vohra S, Badlani G. Balanitis and balanoposthitis. Urol Clin North Am 1992;19:143-147.

15. In: Montgomery J. Dermatopathology. Vol 2. London: Harper \& Row; 1967:988.

16. Petersen CS, Thomsen K. Fusidic acid cream in the treatment of plasma cell balanitis. J Am Acad Dermatol 1992;27:633-634.

17. In: Walsh PC, et al. editor. CampbellÚs Urology 7th Ed. Philadelphia PA: WB Saunders; 1998:729.

18. Fitzpatrick RE, Ruiz-Esparza J, Goldman MP. The depth of thermal necrosis using the $\mathrm{CO}_{2}$ laser. J Dermatol Surg Oncol 1991;17:340-344.

19. Kaufmann R, Hartmann A, Hibst R. Cutting and skin ablative properties of pulsed mid-infrared laser surgery. J Dermatol Surg Oncol 1994;20:112-118.

20. Walsh JT, Deutsch TF. Er:YAG laser ablation of tissue: Measurement of ablation rates. Lasers Surg Med 1989;9: 327-337.

21. Walsh JT, Flotte TJ, Deutsch TF. Er:YAG laser ablation of tissue: Effect of pulse duration and tissue type on thermal damage. Lasers Surg Med 1989;9:314-326.

22. Kaufmann R, Hibst R. Pulsed Er:YAG and 308 nm UVExcimer laser: An in vitro and in vivo study of skin ablative effect. Lasers Surg Med 1989;9:132-140.

23. Kaufmann R, Hibst R. Pulsed $2.94 \mu \mathrm{m}$ Erbium:YAG laser skin ablation: Experimental results and first clinical application. Clin Exp Dermatol 1990;15:389-393. 
24. Hibst R, Kaufmann R. Effects of laser parameters on pulsed Er:YAG laser skin ablation. Lasers Med Sci 1991;6:391397.

25. Ross EV, Naseef GS, McKinlay JR, et al. Comparison of carbon dioxide laser, erbium:YAG laser, dermabrasion and dermatome. A study of thermal damage, wound contraction, and wound healing in a live pig model: Implications for skin resurfacing. J Am Acad Dermatol 2000;42:92105.

26. Aretz HT, Parham CW, Peretti G, et al. Comparison of healing skin lesions induced by Erbium:YAG laser versus scalpel. Lasers Surg Med 1989;9:34A.

27. Jaffe BH, Walsh JT. Water flux from partial-thickness skin wounds: Comparative study of the effects of Er:YAG and Ho:YAG lasers. Lasers Surg Med 1996;18:1-9.

28. Kaufmann R, Hibst R. Pulsed erbium:YAG laser ablation in cutaneous surgery. Lasers Surg Med 1996;19:324-330.

29. Alster TS. Clinical and histologic evaluation of six erbium: YAG lasers for cutaneous resurfacing. Lasers Surg Med $1999 ; 24: 87-92$

30. Hibst R, Stock K, Kaufmann R. Ablation and controlled heating of skin with the Er:YAG laser. Lasers Surg Med 1997;21(Suppl 9):40.

31. Hohenleutner V, Hohenleutner S, Baumler W, et al. Fast and effective skin ablation with an Er:YAG laser: Determination of ablation rates and thermal damage zones. Lasers Surg Med 1997;20:242-247.

32. Utley DS, Koch RJ, Egbert BM. Histologic analysis of the thermal effect on epidermal and dermal structures following treatment with the superpulsed $\mathrm{CO}_{2}$ laser and the erbium:YAG laser: An in vivo study. Lasers Surg Med 1999;24:93.

33. Khatri KA, Ross EV, Grevelink JM, et al. Comparison of erbium:YAG and carbon dioxide lasers in resurfacing of facial rhytides. Arch Dermatol 1999;135:391-397.

34. de Noronha L, Wei Kin Chin E, Menini CM, et al. Histopathologic and morphometric evaluation of the skin abnormalities induced by Erbium:YAG and carbon dioxide lasers in 10 patients. Plast Reconstr Surg 2001;108:1380-1388.

35. Perez M, Bank DE, Silvers D. Skin resurfacing of the face with the Erbium:YAG laser. Dermatol Surg 1998;24:653659.

36. Hale GM, Querry MR. Optical constants of water in the 200 $\mathrm{nm}$ to $200 \mu \mathrm{m}$ wavelength region. Appl Optics 1973;12:555563.

37. Walsh JT, Cummings JP. Effect of the dynamic optical properties of water on midinfrared laser ablation. Lasers Surg Med 1994;15:295-305.

38. Majaron B, Srinivas SM, Huang HL, et al. Deep coagulation of dermal collagen with repetitive Er:YAG laser irradiation. Lasers Surg Med 2000;26:215-222. 